\title{
Generalized Lichen nitidus associated with Down's syndrome - Case report
} Liquen nítido geneneralizado associado à síndrome de Down - Relato de caso

\author{
Luciane Francisca Fernandes Botelho ${ }^{1}$ \\ Marília Marufuji Ogawa ${ }^{3}$ \\ Silmara da Costa Pereira Cestari ${ }^{5}$
}

\author{
João Paulo Junqueira de Magalhães ${ }^{2}$ \\ Milvia Maria Silva Simões Enokihara ${ }^{4}$
}

\begin{abstract}
Lichen nitidus is a disease of unknown etiology, characterized by flesh-colored, shiny papules of 1-2 mm and generally asymptomatic or with mild pruritus. The most common sites of occurrence are genitalia, upper limbs, trunk and abdomen. The generalized form is rare. This is the fourth reported case of lichen nitidus associated with Down Syndrome.

Keywords: Down syndrome; Lichen nitidus; Lichenoid eruptions; Lichens

Resumo: Líquen nítido é uma doença de etiologia desconhecida, caracterizada por pápulas normocrômicas, brilhantes medindo de 1 a 2 milímetros de diâmetro, geralmente assintomáticas ou com leve prurido. A forma mais comum é a localizada nos genitais, membros superiores, tronco e abdome. A forma generalizada é rara. Este é o quarto relato de caso descrito de líquen nítido associado à Síndrome de Down.

Palavras-chave: Erupções liquenóides; Líquen nítido; Liquens; Síndrome de Down
\end{abstract}

\section{INTRODUCTION}

Lichen nitidus is a disease of unknown etiology, first described in 1907 by Pinkus. It is characterized by flesh-colored, shiny papules of $1-2 \mathrm{~mm}$. The localized form affects preferentially the genitalia, upper limbs, trunk and abdomen. There is no sex or race predilection, but it is more common among children and young adults. ${ }^{1}$ It is generally asymptomatic but discrete itching might occur. The prognosis is favorable with spontaneous resolution in the majority of cases. ${ }^{1,2,3}$ Koebner phenomenon can be present. ${ }^{3}$ There are clinical variations including confluent, vesicular, hemorrhagic, palmoplantar, spinous follicular, perforating, linear and generalized forms. ${ }^{1,3}$ The generalized forms are rare and the association with Down's syndrome has been reported in the literature, but it is not clearly understood. ${ }^{2,4,5}$

\section{CASE REPORT}

A 4 year-old, female, black Brazilian patient presented asymptomatic lesions on trunk that appeared three years ago and subsequently became generalized. The patient was born with Down's syndrome and

Received on 12.04.2011.

Approved by the Advisory Board and accepted for publication on 17.07.2011.

* Study carried out at the Dermatology Outpatient Clinic, Federal University of São Paulo (Universidade Federal de São Paulo - UNIFESP) - São Paulo (SP), Brazil. Conflict of interest: None

Financial funding: None

M.D - Specializing in dermatoscopy and cutaneous tumors - Federal University of São Paulo (Universidade Federal de São Paulo - UNIFESP) - São Paulo (SP), Brazil. M.D - Specializing in advanced dermatology - Federal University of São Paulo (Universidade Federal de São Paulo - UNIFESP) - São Paulo (SP), Brazil.

M.D - Dermatologist at the Federal University of São Paulo (Universidade Federal de São Paulo - UNIFESP) - São Paulo (SP), Brazil.

Ph.D - Dermatopathologist physician at the Federal University of São Paulo (Universidade Federal de São Paulo - UNIFESP) - São Paulo (SP), Brazil

Ph.D - Adjunct Professor of the Dermatology Department, Paulista School of Medicine, Federal University of São Paulo (Universidade Federal de São Paulo EPM-UNIFESP). Head of the Infectious and Parasitary Dermatology Discipline - Federal University of São Paulo (Universidade Federal de São Paulo - UNIFESP) - São Paulo (SP), Brazil. 
hypothyroidism. On physical examination 1-2 mm hypochromic, shiny papules were distributed on face, trunk, upper and lower limbs and genitalia (Figures 1 and 2). Palmoplantar areas were spared (Figure 3). The histopathological study showed lymphohistiocytic granulomatous infiltrate focally enlarging papillary dermis, limited by lateral epidermal ridges resembling a "claw" or "baseball glove and ball" image (Figures 4 and 5). The clinical-pathological correlation was compatible with lichen nitidus. The patient was treated with moisturizing cream and had discrete improvement after a two-month follow-up.

\section{DISCUSSION}

To our knowledge this is the fourth case reported in the literature associating generalized lichen nitidus and Down's syndrome. The first case was described by Patrizi et al. in 1991 and the subsequent reports were done by Laxmisha \& Thappa and Henry $\&$ Metry. ${ }^{2,4,5}$ All reported cases were on children and only one presented pruritus. ${ }^{2}$ Koebner phenomenon was present in one case. ${ }^{5}$ The proposed treatments, mostly for isolated cases included topical steroids, ammonium lactate lotion, topical immunomodulators and oral cetirizin. In this case we prescribed moisturizing cream because there were no symptoms. Some authors suggest that lichen nitidus is a lichen planus variant. ${ }^{3,6}$ The co-existence of two entities has already been described and in some cases lichen nitidus can progress into lichen planus. ${ }^{1,3}$ However, these entities have distinctive clinical and histological characteristics. Smoller \& Flynn demonstrated that the infiltrate was different on lichen nitidus and lichen planus biopsy samples, using immunohistochemical techniques. ${ }^{6}$ The histopathology of lichen nitidus is characteristic, showing lymphohistiocytic granulomatous infiltrate

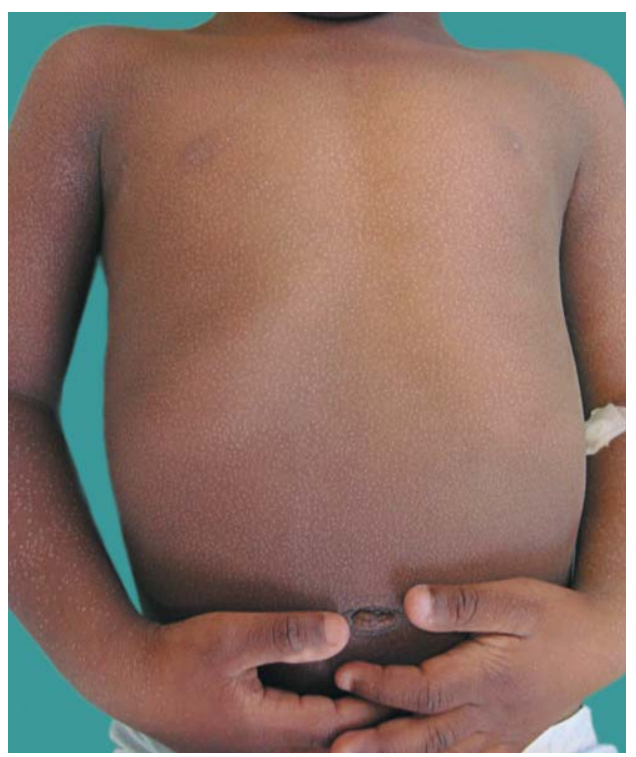

Figure 1: Disseminated hypochromic papules wtih shiny surface

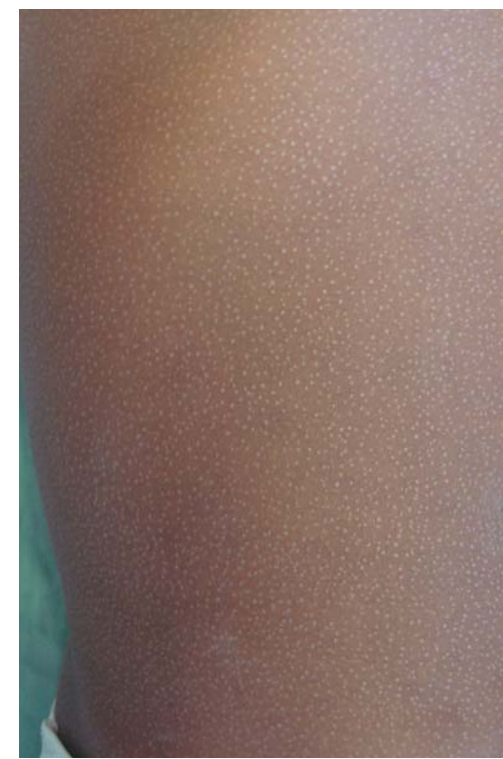

FIGURE 2: Closer view shows 1-2 $\mathrm{mm}$ hypochromic papules, with shiny surface distributed on abdomen

limited to papillary dermis. The epidermal ridges are thickened into dermis involving the infiltrate that resembles the "baseball glove and ball" image. ${ }^{3}$

Cutaneous alterations described in patients with Down's syndrome include: atopic dermatitis, milia-like calcinosis cutis, elastosis perforans serpiginosum, onychomycosis, tinea corporis, anetoderma, folliculitis, psoriasis, cheilitis, xeroderma, alopecia areata, palmoplantar hyperkeratosis, syringoma, keratosis pilares, vitiligo, seborrheic dermatitis and livedo.

${ }^{7}$ Generalized lichen nitidus has already been described in association with Crohn's disease, amenorrhea and after treatment with alpha interferon. ${ }^{8,9,10}$ These reports are sporadic and no relationship between lichen nitidus and systemic disease has been established. The proposed treatments in the literature have

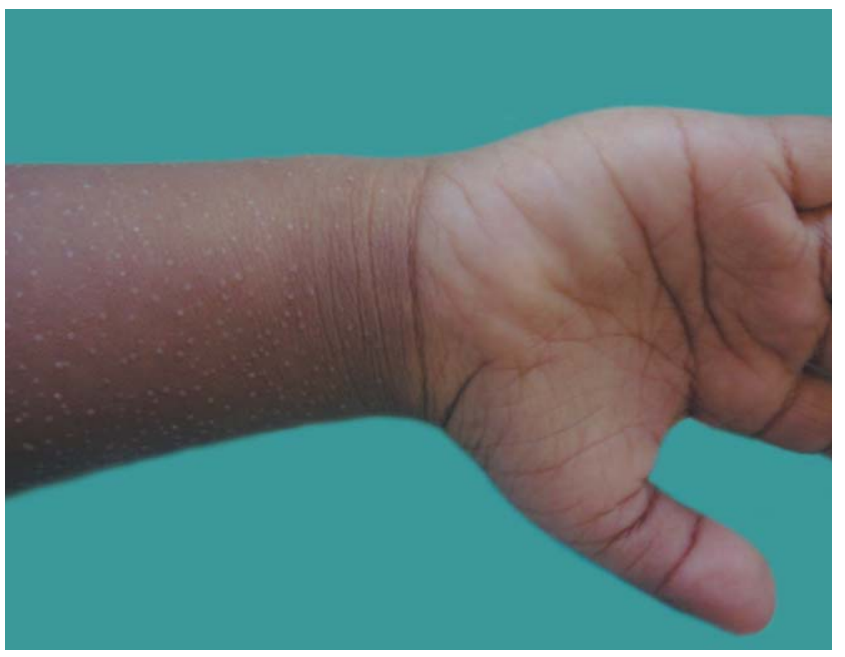

Figure 3: Hypochromic shiny papules sparing palmar surface 


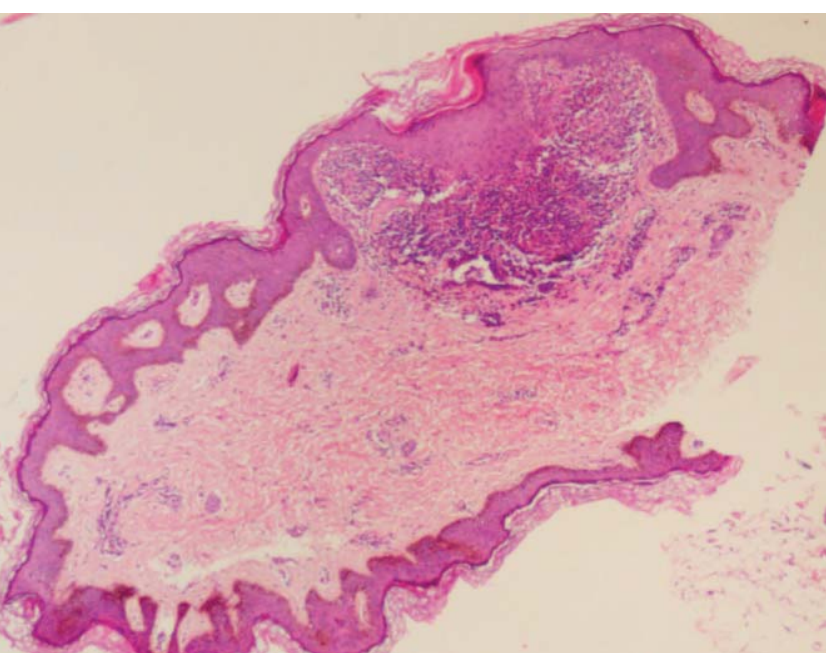

FigURE 4: (HE 40X) Presence of granuloma focally enlarging papillary dermis limited by epidermal ridges forming the "claw image"

inconstant results, but good outcomes were described with PUVA, UVB narrow band, astemizole, topical and systemic steroids, oral antihistamines and cyclosporin. ${ }^{1,2,5,6}$ Despite these treatments, we considered an expectant observation of asymptomatic cases as a good option, since spontaneous resolution has been

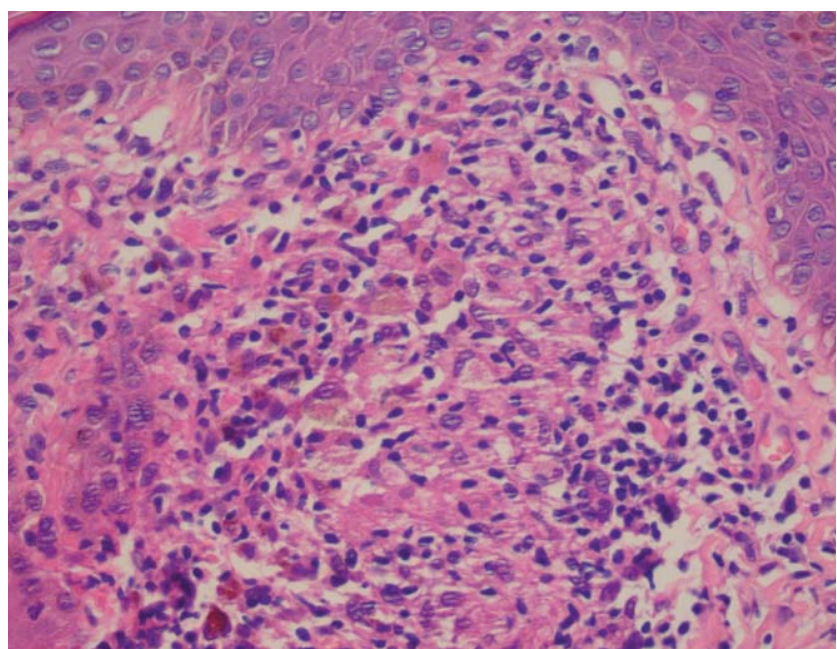

Figure 5: (HE 400X) Papillary dermis granuloma compound with histiocytic center and lymphocytic halo

reported in the literature. ${ }^{1,6}$ We present this case because of the rare association between Down's syndrome and generalized lichen nitidus. Further studies are necessary to explain if this association is just a coincidence.

\section{REFERENCES}

1. Chen W, Schramm M, Zouboulis CC. Generalized lichen nitidus. J Am Acad Dermatol. 1997:36:630-1.

2. Laxmisha C, Thappa DM. Generalized lichen nitidus with Down syndrome. J Eur Acad Dermatol Venereol. 2006:20:1156-7.

3. Frey MN, Bonamigo RR, Luzzatto L, Machado RB, Seidel GB. Case for diagnosis. Generalized lichen nitidus in childhood. An Bras Dermatol. 2010;85:561-3.

4. Patrizi A, Dilernia V, Pauluzzi P. Generalized lichen nitidus, trysomy-21 and congenital megacolon. Ann Dermatol Venereol. 1991;118:725.

5. Henry M, Metry DW. Generalized lichen nitidus in association with Down Syndrome. Pediatr Dermatol. 2009;26:109-11.

6. Smoller BR, Flynn TC. Immunohistochemical examination of lichen nitidus suggests that it is not a localized papular variant of lichen planus. J Am Acad Dermatol. 1992;27:232-6

7. Madan V, Williams J, Lear JT. Dermatological manifestations of Down's syndrome. Clin Exp Dermatol. 2006;31:623-9.

8. Kint A, Meysman L, Bugingo G, Verdonk G, Hublé F. Lichen nitidus and Crohn's disease. Dermatologica. 1982:164:272-7.
9. Taniguchi S, Chanoki M, Hamada T. Recurrent generalized lichen nitidus associated with amenorrhea. Acta Derm Venereol. 1994;74:224-5.

10. Scheler M, Proelss J, Bräuninger W, Bieber T, Wenzel J. Generalized lichen nitidus with involvement of the palms following interferon alpha treatment. Dermatology. 2007:215:236-9

\author{
MAILING ADDRESS: \\ Luciane Francisca Fernandes Botelho \\ Rua Borges Lagoa 508 \\ 04038-001 Vila Clementino - São Paulo, SP. \\ E-mail: lucianebotelho@hotmail.com
}

How to cite this article: Botelho LFF, Afonso JPJM, Ogawa MM, Enokihara MMSS, Cestari SCP. Generalized Lichen nitidus associated with Down's syndrome: case report. An Bras Dermatol. 2012;87(3):466-8. 